\begin{tabular}{c} 
International Journal of Engineering \& Technology, $7(2)(2018) 714-717$ \\
SPC \\
International Journal of Engineering \& Technology \\
Website $\begin{array}{c}\text { www.sciencepubco.com/index.php/IJET } \\
\text { doi: } 10.14419 / \text { ijet.v7i2.10817 } \\
\text { Research paper }\end{array}$ \\
\hline
\end{tabular}

\title{
User-friendly novel method of geopolymer concrete production mixes
}

\author{
Akshay sabu ${ }^{1}$, Dr.N.P. Rajamane ${ }^{1}$ \\ ${ }^{1}$ Department of Civil Engineering,SRM University,KattankulathurFaculty of Engineering and \\ Technology,SRM University, Kattankulathur \\ *Corresponding author E-mail:sabuakshay@gmail.com
}

\begin{abstract}
Geopolymer is an inorganic polymer, which can perform as an effective binder in place of Portland cement. With this, the Geopolymer concrete has become highly Ecofriendly with very low carbon footprint. The GPC formulation at present utilises industrial waste materials like fly ash and GGBS, which are activated with well-proportioned alkaline liquid. At present the commercially available lye and Sodium Silicate solution are used to prepare alkaline liquid capable of initiating geopolymer reaction. It is noticed that the liquid system has limited shelf life by making field production of Geopolymer concrete mixes was a difficult one more over the liquid system and its ingredients are difficult to transport over longer distances. This has been the main obstacle for development of large-scale applications of GPC mixes on commercial basis. This issue was addressed in the present study by using solid activator in replacement of liquid solution. The solid activating system can be produced just before the preparation of fresh GPC mixes at anyway at any time. It is found that the mechanical strength $(40-45 \mathrm{Mpa})$ property was similar to the liquid activating GPC mixes. This new technique of production of GPC mixes using solid activators can be consider as the major breakthrough for commercialization / large scale field applications of Geopolymer technology.
\end{abstract}

Keywords: Geopolymer; Fly ASH; GGBS; Compressive Strength

\section{Introduction}

Geopolymer term was initially coined by French material scientist J,Davidovits in the year 1979. Geopolymer binder is an innovative and eco-friendly construction material and an alternative to Portland cement binder. As per the latest report by National Control of Pollution Board, the Ordinary Portland cement emits about 868 million tonnes of $\mathrm{CO}_{2}$. So in order to reduce the emission of $\mathrm{CO}_{2}$ the idea of using geopolymer concrete was done. Both Fly ash and GGBS are processed by appropriate technology and used for concrete works reducing the emission of $\mathrm{CO}_{2}$ by Ordinary Portland Concrete. The geopolymer concrete is composed of fly ash, GGBS (Granulated blast furnace slag) and an Alkaline Activator solution, whichis mainly made up of liquid sodium silicate solution available commercially in the market. It is one of the major constituents of geopolymer source material since it activates the geopolymeric source materials containing silica and aluminium such as Fly ash and GGBS. AAS(alkaline activator solution) is mainly used as liquid binder in the concrete is also called as RGL(Reaction Generating Liquid). Geopolymer can be considered as an eco-friendly concrete since it uses the waste materials emissions from coal power plants that is flyash and GGBS which is a residue of ceramic industries, therefore a sustainable environment is created by recycling the waste products from the following factories. Geopolymer concrete is also anself curing concrete since it requires no water and can be demoulded within 3 to $4 \mathrm{hrs}$ after casting. In this paper the prime focus is on replacing the Liquid sodium silicate solution by Solid sodium silicate. Since the transportation and handling of liquid solution to the site is a factor of major concern plan has been made to make the solid sodium silicate solution in site itself and use it for geopolymer concrete production.Recent literature studies done by "FN Okoye[6]" reveals that silicates increases the compressive strength. Previous studies has been done with the help of liquid silicate solutions by "E.Kamseui,MandeepkaurJaswal[9], [10]" so the idea is to replace the liquid silicate with solid sodium silicate solution and compare the compressive strengths.In the following paper we will discuss about the use of sodium metasilicate with different grades of $\mathrm{Na}_{2} \mathrm{SiO}_{3} .5 \mathrm{H}_{2} \mathrm{O}$ (RGL3), $7 \mathrm{H}_{2} \mathrm{O}$ (RGL2) and $9 \mathrm{H}_{2} \mathrm{O}$ (RGL1) and compare the strength it hasobtained with that of normal RGL.RGL 3 has been considered to be superior than other two RGLs and its compressive strength is almost similar to that of normal RGL.It also discusses about strength change with different mix proportions of Flyash and GGBS used in RGL3.The following project will be a good breakthrough in the field of Geopolymer concrete production and it will be economical as there is no requirement of liquid silicate solution transportation.

The major objective of the paper is to revolutionize the geopolymer concrete industry by replacing the liquid silicate solution with solid sodium silicate by making it on the site ,making the production of geopolymer concrete economical and viable.The transportation cost for solution will be significantly reduced. Thus it will make the production of geopolymer concrete more bulkier and economical.

\section{Materials and mix design}

\subsection{Materials}


Geopolymeric source material used in the present work is Class C fly ash from Ennore thermal power plant,India and GGBS from the Jindal power plant. The fine aggregate used is river sand has been used here as a fine aggregate with a sieve of $4.75 \mathrm{~mm}$. The coarse aggregates used for casting purposes are of size $10 \mathrm{~mm}$ and $12 \mathrm{~mm}$.

\subsection{Reaction generating liquid}

Reaction generating liquid is tradionally prepared by mixing the sodium silicate solution (MR: 2.2 ) with Nao (50\% lye) and it is denoted as RGL.

A novel method of preparing RGL by solid sodium silicate powder as follows:

Sodium metasilicate mixed with distilled water of grades $\mathrm{Na}_{2} \mathrm{SiO}_{3} .9 \mathrm{H}_{2} \mathrm{O}$ (RGL1), $\mathrm{Na}_{2} \mathrm{SiO}_{3} 7 \mathrm{H}_{2} \mathrm{O}$ (RGL 2) and $\mathrm{Na}_{2} \mathrm{SiO}_{3} 5 \mathrm{H}_{2} \mathrm{O}$ (RGL 3)followed by the $\mathrm{NaOH}$ addition respectively.The Physiochemical properties of the RGL are listed in table.1 mentioned below:

Table1: Physico-Chemical Properties of RGL

\begin{tabular}{|c|c|c|c|c|c|c|}
\hline \multirow{2}{*}{ S.no } & \multirow{2}{*}{ Composition } & \multirow{2}{*}{$\begin{array}{l}\text { Physical properties } \\
\text { Appearance }\end{array}$} & \multirow[b]{2}{*}{ Shape } & \multicolumn{3}{|c|}{ Chemical Composition } \\
\hline & & & & $\mathrm{Na}_{2} \mathrm{O}_{3}$ & $\mathrm{SiO}_{2}$ & $\mathrm{H}_{2} \mathrm{O}$ \\
\hline 1. & $\mathrm{Na}_{2} \mathrm{SiO}_{3} 9 \mathrm{H}_{2} \mathrm{O}$ & White Shape & Crystalline & $22 \%$ & $22 \%$ & $66 \%$ \\
\hline 2 & $\mathrm{Na}_{2} \mathrm{SiO}_{3} 7 \mathrm{H}_{2} \mathrm{O}$ & Cream Colour Powder & Crystalline & $24 \%$ & $25 \%$ & $51 \%$ \\
\hline 4 & $\mathrm{Na}_{2} \mathrm{SiO}_{3}$ & White transparent fluid & Crystalline & $15 \%$ & $30 \%$ & $55 \%$ \\
\hline
\end{tabular}

\subsection{Mix design}

\begin{tabular}{lcc}
\hline Fly Ash/GGBS $\left(\mathrm{kg} / \mathrm{m}^{3}\right)$ & Fine Aggregate $\left(\mathrm{kg} / \mathrm{m}^{3}\right)$ & Co \\
\hline 407 & 647 & 1056 \\
\hline 3. Experimental programme &
\end{tabular}

\section{Experimental programme}

This paper discusses about the various experimental works that has been done with the use of different RGLs (RGL1,RGL2 and RGL3) and comparing the strength with normal RGL.Initially the RGL mix was prepared of mix ratio 1:4:10 which composes of 1 lye, 4 metasilicate and 10 distilled water.The various specimens has been casted with different RGLs of same mix and the strength was compared.The RGL3 of grade $5 \mathrm{H}_{2} \mathrm{O}$ was selected among the following RGLs considering its availability factor and strength.In the next phase the specimens were casted using RGL 3 with different mix proportions of fly ash and GGBS in the ratio of 50:50 and 80:20.Change in strength was studied with the mix proportions of 50:50 and 80:20. Various specimens were casted using the mix proportions of 50:50 and 80:20 and its properties were studied.The strength was calculated for 3, 7 and 28 days.Earlier studies were done by "G.Naidu,V.Prasad [19]" to improve the strength properties.

The normal RGL used is of ratio 1:2:7.RGL 1,2 and 3 was prepared in the lab.RGL was prepared in the mix ratio of 1:4:10,which means 1 sodium hydroxide flakes, 4 water and 10 $\mathrm{H}_{2} \mathrm{O}$. The liquid solution is having a molar ratio of 2.5.The compressive strength test was done for the specimens and its strength were compared.Earlier powder preparation was done by using inorganic cement based activates slag was done by "Kaituo Wang [4]".He has discussed the use of solid watch glass for preparation of RGL solution.

\section{Results and discussion}

\subsection{Characterisation of RGL}

\subsubsection{Temperature and solubility test}

Initially solubility test was done for the various RGLs.It was done by initially taking metasilicates and dissolving it in a certain quantity of water.Themetasilicates was added slowly and the solution was stirred properly so that metasilicate gets completely dissolved in water and after 2 to 3 minutes sodium hydroxide flakes was added in the water.During its addition a certain amount of heat was liberated thereby producing exothermic reaction. The solution was stirred properly until it gets a clear solution.In case of RGL 2 it was observed that solution was not getting dissolved to a certain extent and some materials were getting precipitated at bottom.The temperature was noted during the addition of flakes.To improve the polymerisation reaction in sodium silicate solution, high temperature is required as discussed in "[2-4]".

Coarse Aggregate $\left(\mathrm{kg} / \mathrm{m}^{3}\right) \quad$ RGL $\left(\mathrm{kg} / \mathrm{m}^{3}\right) \quad$ L/S ratio

$233 \quad 0.55$

The temperature tests of various solutions has been observed when the flakes were added into it.The temperature was noted for the solutions with grade composition of $5 \mathrm{H}_{2} \mathrm{O}, 7 \mathrm{H}_{2} \mathrm{O}$ and $9 \mathrm{H}_{2} \mathrm{O}$. First of all the temperature was noted for the mix with powder composition of $9 \mathrm{H}_{2} \mathrm{O}$.Initially the room temperature was noted.The room temperature before adding the flakes was $33^{\circ}$ Celsius.After adding the flakes the temperature drastically increased by 4 to 5degrees.The temperature of the solution was measured using infrared thermometer.It was observerd that there is an increase of 4 to 5 degree more than room temperature after adding the flakes. Similarly the temperature test was done for $7 \mathrm{H}_{2} \mathrm{O}$ and it was observed that there was only a marginal increase of 3 to 4 degrees only.After making the RGL mix with $5 \mathrm{H}_{2} \mathrm{O}$, the temperature test was done after adding $200 \mathrm{~g}$ flakes and $400 \mathrm{~g}$ flakes into it.It was observed that the temperature gone very high after adding the flakes in the mix.The initial room temperature was $28^{\circ}$ celsius and after adding the flakes it was observed that the temperature was around $45^{\circ}$ celsius.It is observed that there is a high increase in temperature with RGL mix containing $5 \mathrm{H}_{2} \mathrm{O}$.

\subsection{Compressive strength test results for RGLS}

The Compressive strength test result has been done for specimens made of different RGLs. The compressive strength of the specimen was checked for 7,14 and 28 days.The L/S ratio of specimen was 0.55 while for RGL 2 the L/S ratio was 0.6.

The $100 \mathrm{~mm}$ cube specimens has been casted by using the different RGLs.The different parameters such as solubility and temperature were considered while casting.

\subsubsection{Workability of RGLs}

It has been observed that RGL 3 had been giving a better workability when compared to the normal RGL.The workability mix of RGL 1 and RGL 2 was good.

\begin{tabular}{|c|c|c|c|}
\hline Mix ID & Age & Average Compressive Strength(Mpa) & $\mathrm{L} / \mathrm{S}$ ratio \\
\hline \multirow{3}{*}{ RGL } & 7 & 38.6 & \multirow{3}{*}{0.55} \\
\hline & 14 & 42.3 & \\
\hline & 28 & 50.86 & \\
\hline \multirow{3}{*}{ RGL 1} & 7 & 34 & \multirow{4}{*}{0.55} \\
\hline & 14 & 38.7 & \\
\hline & 28 & 46 & \\
\hline \multirow{3}{*}{ RGL 2} & 7 & 5.5 & \\
\hline & 14 & 4.7 & \multirow[t]{2}{*}{0.6} \\
\hline & 28 & 4.4 & \\
\hline \multirow{3}{*}{ RGL 3} & 7 & 34.36 & \multirow{3}{*}{0.55} \\
\hline & 14 & 38.73 & \\
\hline & 28 & 47.2 & \\
\hline
\end{tabular}




\subsubsection{Strength analysis}

From the above results we can get a clear idea about the compressive strength of different RGLs.The calculation of compressive strength was done for specimen of $100 \mathrm{~mm}$ cube size.There was a considerable strength reduction for RGL 2 while RGL 1 and RGL 3 was giving a fair Strength when compared with that of RGL.RGL 1 is not available commercially in the market.The material available is of laboratory grade,While RGL 2 and RGL 3 available is of commercial grade.It was observed that strength of RGL 2 was considerably lower when compared to the other RGLs. Since strength reduction was higher, it was not a good idea to use RGL 2.

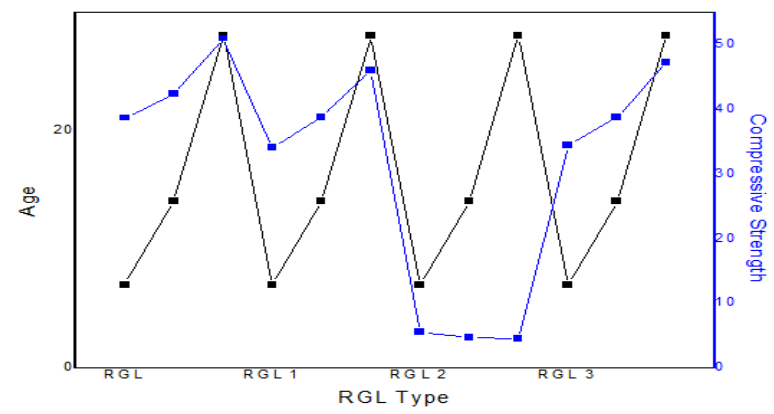

Compressive Strength Variations in Different Rgls.

\subsubsection{Cost analysis}

Comparing the cost of different RGLs, RGL 3 was compared to be cheaper than the otherRGLs.RGL is liquid solution and its transportation and handling is difficult compared to the other RGLs, While RGL 1 available is of laboratory grade and is not available commercially in the market.RGL 2 and RGL 3 are available commercially in the market but citing the strength reduction of RGL 2,RGL 3 is preffered.RGL 3 is available within the market commercially.

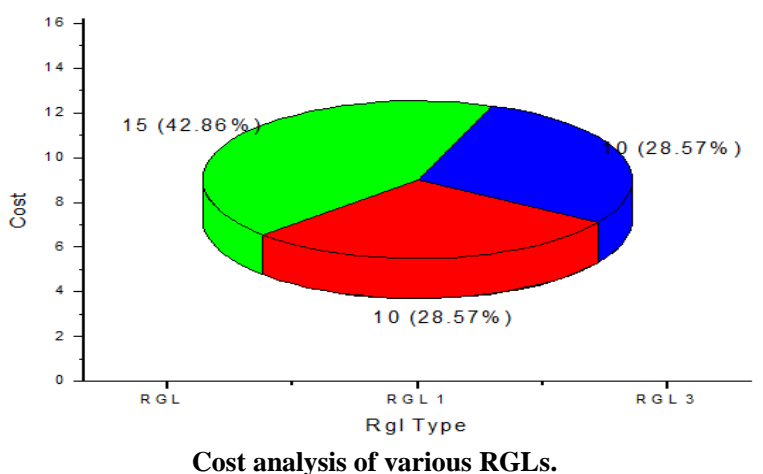

From the above results we can select the RGL 3 mix since it was easily available in the market.The strength of RGL 3 was better with respect to the other two RGLs.The various cylindrical specimens of $100 \mathrm{~mm}$ dimension were casted usingRGL 3 and its compressive strength was compared as that of normal RGL.

\subsubsection{Availability and convenience}

The RGL 3 solution is easily available and is convenient. The solution does not require proper handling and care since it is available in the solid form and there is easiness in transporting the solid material to site. Thus the transportation cost of the material can be reduced to a further extent based on its easy availability.

\subsubsection{Storage of materials}

Since the material is available in solid form the storage of material is not a matter of concern while the liquid solution has to be stored in a container. The solution is prepared by using the raw materials available commercially and is immediately mixed into the concrete.

\subsection{Compressive strength study of different RGLs on cylinder specimens $(100 \mathrm{~mm})$}

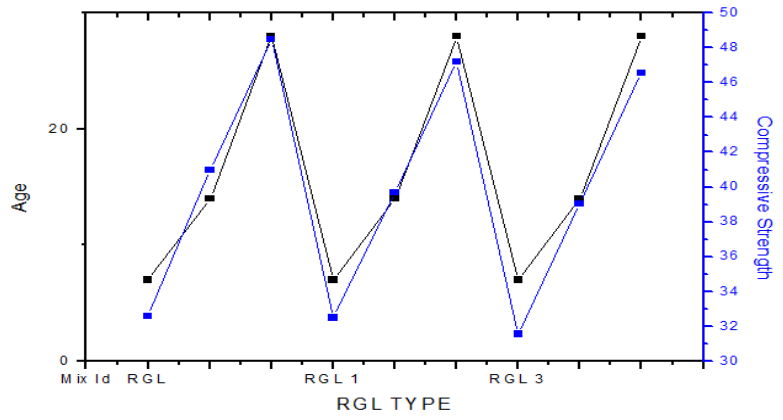

4.3.1. Characteristics of compressive strength with different RGLs on cylinders

From the graphical analysis it can be said that RGL 1 and RGL 3 have fair strength when compared to the normal RGL.The strength of around $47 \mathrm{Mpa}$ is obtained after a period of 28 days. The L/S ratio was 0.5 .The cylindrical specimens used for casting was of $100 \mathrm{~mm}$ diameter.

\section{Conclusion}

The Compressive strength of different RGlsis studied from this paper.From the results available it indicates that there is a scope to use the solid sodium silicate instead of using the liquid silicate solution.Compressive strength of different RGLs indicate that RGL3 has a better performance considering its strength,availability and cost factors. The strength of RGL 3 was almost similar to that of normal RGL.The RGL 3 solution is easy to make hence it is time saving.It easily binds the aluminosilicate particles.Thus with the help of available data we can say that RGL 3 can be used as a better alternative to that of normal RGL.

\section{References}

[1] N.Essaidi, L.Laou, S.Yotte,S.Rossignol May2016,Comparative study of various methods of preparation of silicate solutionand its effect on depolymerisationreaction, Results in Physics Vol 6,280287.https://doi.org/10.1016/j.rinp.2016.05.006.

[2] D.Dimas,D.paniasjuly 2009 ,Polymerisation in sodium silicate solution, a fundamental process in geopolymerisation technology, Journal of material science Vol.44,Issue 14,pp 3719-3730.

[3] HonglingWang,Effect of Sodium silicate in Flexure and Shear bond of Geopolymer + concrete $6^{\text {th }}$ july2004, Journal Colloids and surfaces:A physiochemical and engineering aspects.

[4] Kaituo Wang 1May 2017, Preparation of drying Powder inorganic polymer cement based on alkali activated slag technology,Powder technology Vol 312 pages 204-209.

[5] Tanakorn,AkiharoMaggawa,Effect of sodium hydroxide and sodium silicate solutions on compressive and shear bond strengths of FA-GGBS Concrete dtd Jan2015 published in Construction and building materials

[6] FN Okoye,JDurgaprasad and N.B.Singh,Effect of Silica Fume on the mechanical properties of flyash based geopolymer concrete,Ceramics International dtd October 2015 Vol 42 pages 30003006.

[7] Ana Passuello,ErichD.Rodriguezdtd 10 November 2017,Evaluation of potential improvement in the environmental footprint of geopolymers using waste derived activators, Journal of cleaner production, Vol 166 pages 680-689.

[8] N.B.Singh,MukeshSaxena ,Effect of nanomaterials on the properties of geopolymer mortars and concrete,Materials today precedings, Vol 5, issue 3,part 1,2018,pages 9035-9040.

[9] MandeepKaur,Jaspal Singh dtd 1 Feb 2018,Synthesis of fly ash based geopolymer mortars considering different concentration and 
combination of alkaline activator solution,Construction and building materials, Vol 91,30 Aug 2015,pages 1-8.

[10] E.Kamseu,M.Canniodtd $20^{\text {th }}$ January 2017,Substitution of sodium silicate with rice husk ash $\mathrm{NaOH}$ solution in metakaolin based geopolymer cement concerning reduction in global warming,Journey of cleaner productions, Vol 142,part 4,pages 500-509.

[11] Nicoletta Toniolo,AldoR.Boccaccinidtd 1 December 2017,Fly ash based geopolymers containing added silica waste.Areview,CeramicsInternational,Vol 143, Issues 4,pages 56965704

[12] Yun-Ming Liew,Cheng-Yong Heahdtd 15 december 2017,Formation of one part mixing geopolymers and geopolymer ceramics from geopolymer powder,Construction and building materials, Vol 156,pages 9-18.

[13] Candidate, E. I. D. P. D. (2010). Geopolymer Concrete. Concrete Pavment Technology Program, (Davidovits 2008), 1-34.

[14] June, J., Politecnica, U., Lloyd, N. a., Rangan, B. V., Chong, L. F. James, S. P., ... Warren, A. D. (2010). Geopolymer Concrete with Fly Ash. Second International Conference on Sustainable Construction Materials and Technologies, 7(6), 1493-1504.

[15] Laskar, A. I., \&Bhattacharjee, R. (2011). Rheology of fly-ash-based geopolymer concrete. ACI Materials Journal, 108(5), 536-542.

[16] Assi, L. N., Deaver, E., Elbatanouny, M. K., \&Ziehl, P. (2016). Investigation of early compressive strength of fly ash-based geopolymer concrete. Construction and building112, 807-815. https://doi.org/10.1016/j.conbuildmat.2016.03.008.

[17] Vora, P. R., \& Dave, U. V. (2013). Parametric studies on compressive strength of geopolymer concrete. In Procedia Engineering (Vol. 51, pp. 210-https://doi.org/10.1016/j.proeng.2013.01.030.

[18] Okoye, F. N., Durgaprasad, J., \& Singh, N. B. (2015). Effect of silica fume on the mechanical properties of fly ash based-geopolymer concrete. Ceramics International, 1-7. https://doi.org/10.1016/j.ceramint.2015.10.084.

[19] V Naidu, G., Prasad, a S. S. N., Adiseshu, S., \&Satayanarayana, P. V. V. (2012). A Study on Strength Properties of Geopolymer Concrete with Addition of G.G.B.S. International Journal of Engineering Research and Development, 2(4), 227867.https://doi.org/10.1016/j.ceramint.2015.10.084. 